\title{
Synthesis, Characterization and toxicity Analysis of Novel Silver Nanoparticles from Brassica oleracea var italica (Broccoli) ${ }^{\dagger}$
}

\author{
Bavanilatha Muthiah ${ }^{1}$, Yoshitha Lakshmanan ${ }^{1, *}$, Valli Nachiyar ${ }^{1}$, Sudha S. ${ }^{1}$ \\ 1 Department of Biotechnology, Sathyabama Institute of Science and Technology, Jeppiaar Nagar, Raajiv Gandhi Salai, \\ Chennai, Tamil Nadu, 600 119, India \\ * Correspondence: yoshithalakshmanan@gmail.com; \\ $\uparrow \quad$ Presented at International Conference on Bioengineering for Health and Environment (ICBHE 2020)
}

Received: 5.07.2020; Revised: 10.07.2020; Accepted: 12.07.2020; Published: 15.07.2020

\begin{abstract}
Epidemiologic studies demonstrate that vegetable consumption decreases the risk of various types of cancers. Crucifers were found to have anti-cancer and antioxidant activities due to their enriched content of glycosylates. Nanotechnology is the design, characterization, production \& application of structures, devices, and systems by controlling shape and size at the nanoscale. This work describes a novel combinatorial synthesis approach, which is rapid and simple for the synthesis of metallic nanostructures of novel metals such as silver (Ag) by using a "comparison study of Conventional method (CM) and Microwave (MW) synthesis" method of silver nanoparticles. By the current study, we describe a cost-effective and environment-friendly technique for green synthesis of silver nanoparticles through the extract of Broccoli. AgNPs characterized using UV-Vis absorption spectroscopy was used to monitor the quantitative formation of silver nanoparticles. The characteristics features of the obtained silver nanoparticles were studied using a Scanning electron microscope (SEM), Transmission electron microscope (TEM), Fourier-transform infrared spectroscopy (FTIR). Here, we have reported a simple biological and low-cost approach for the preparation of stable silver nanoparticles by bioreduction of silver nitrate solution using Brassica oleracea (Broccoli) aqueous extract. The in-vitro analysis was performed in HEp 2 cell lines against which anti-cancer activity was recorded. Additionally, the antioxidant activity was also found by estimating the antioxidant enzymes. The in vivo toxicity was performed using chick embryos. The important outcome of the study will be the development of value-added products from cruciferous plants like B. oleracea for nanotechnologybased industries.
\end{abstract}

Keywords: Broccoli; TEM; SEM; UV-Visible spectroscopy; FTIR; Microwave-assisted method.

(C) 2020 by the authors. This article is an open-access article distributed under the terms and conditions of the Creative Commons Attribution (CC BY) license (https://creativecommons.org/licenses/by/4.0/).

\section{Funding}

This research received no external funding.

\section{Acknowledgments}

This research has no acknowledgment.

\section{Conflicts of Interest}

The authors declare no conflict of interest.

https://conferenceproceedings.international 